\title{
Application of AHP in the evaluation of teaching quality in Independent Colleges
}

\author{
Zhihui $\operatorname{Han}^{1, \text { a }}$, Jianhua Zhao ${ }^{2, b}$ \\ ${ }^{1}$ ChangChun University Of Science And Technology, Changchun 130600, China; \\ ${ }^{2}$ ChangChun Normal University, Changchun 130032, China. \\ a sincere_zjh@163.com, ${ }^{\mathrm{b}} 13756840272 @ 163 . c 0 m$
}

Keywords: Independent College, AHP, teaching quality.

\begin{abstract}
Have their own characteristics in the development of independent college, strengthening is an important measure to improve college teaching quality evaluation of teachers' teaching quality. This paper put forward the analytic hierarchy process (AHP) the teachers' teaching quality evaluation system and multi-level evaluation model, the establishment of decision hierarchy structure according to the method of AHP, through the synthesis level weights to build a multi hierarchy decision model, the evaluation of teaching quality of independent college teachers and more reasonable.
\end{abstract}

\section{Introduction}

The independent college is in general universities, according to the Ministry of education "on standardizing and Strengthening General College in new mechanism and running pattern of independent college management a number of opinions" provisions, in accordance with the independent college type machine and mold new of the undergraduate course level. It is of high quality educational resources and the quality of social capital are combined with each other to the undergraduate level, the new mechanism of the formation of a new pattern of regular higher education institutions, is a major breakthrough in ${ }^{[1]}$ reform of school running mechanism innovation and the mode of colleges and universities. They implement the independent legal person qualification, independent teaching and financial management, the independent campus buildings, the independent recruitment of students and independent undergraduate diploma and degree certificates issued.

Characteristics of the independent college has decided its management mode and ordinary colleges and universities should be different, independent college management system and the way of mutually agreed by the applicant and cooperation, especially in the management of the teachers, we should pay more attention to the teacher's teaching level, because it will have a direct impact on school enrollment and employment of students, so pay attention to according to labor payment, the income of contract management, appointment system is the main management measures taken by the majority of independent college.

How can a reasonable evaluation of teaching quality of every teacher, this reference America scholar T. L. Saaty put forward the analytic hierarchy process (AnalyticHierarchy, Process, AHP) of teachers in the teaching process, teaching attitude, teaching basic skills, teaching organization and other factors of the non quantitative evaluation index to describe, to establish the teacher teaching quality evaluation system and multi-level evaluation model, the realization of multi index evaluation on the teaching quality and reasonable.

\section{Teaching in Independent Colleges Based on AHP method of quality evaluation model and algorithm}

The analytic hierarchy process (AHP) is America operational research experts Sarti professor of the University of Pittsburgh (T.L.Saaty) than in the early 70 century, as American defense department study "according to each industrial sector contribution to the national welfare and the power distribution" subject, using multi-objective comprehensive evaluation method and network system 
theory, a kind of hierarchy decision analysis method proposed. The characteristic of this method is the basis of the in-depth analysis and decision making in the internal relationship, the complex factors that affect the essence and so on, the use of less quantitative information to the decision making process of mathematical thinking, so as to provide decision-making method is simple ${ }^{[2]}$ for complex multi criteria decision-making problems, multi-objective or no structural characteristics. The model and method of complex system is difficult to fully quantitative decision-making. The basic method which can be broadly grouped into the following four steps:

(1) Set up a hierarchical structure model;

(2)constructing judgment matrix;

(3)the calculation of relative weights of elements under a single rule;

(4)calculate the combination weights of the layer element.

\subsection{The establishment of teaching quality evaluation hierarchy model.}

First of all, the problem of teaching quality evaluation is decomposed into each component called elements, these elements according to different attributes are divided into several groups, to form different levels. The structure model is shown in fig. 1.

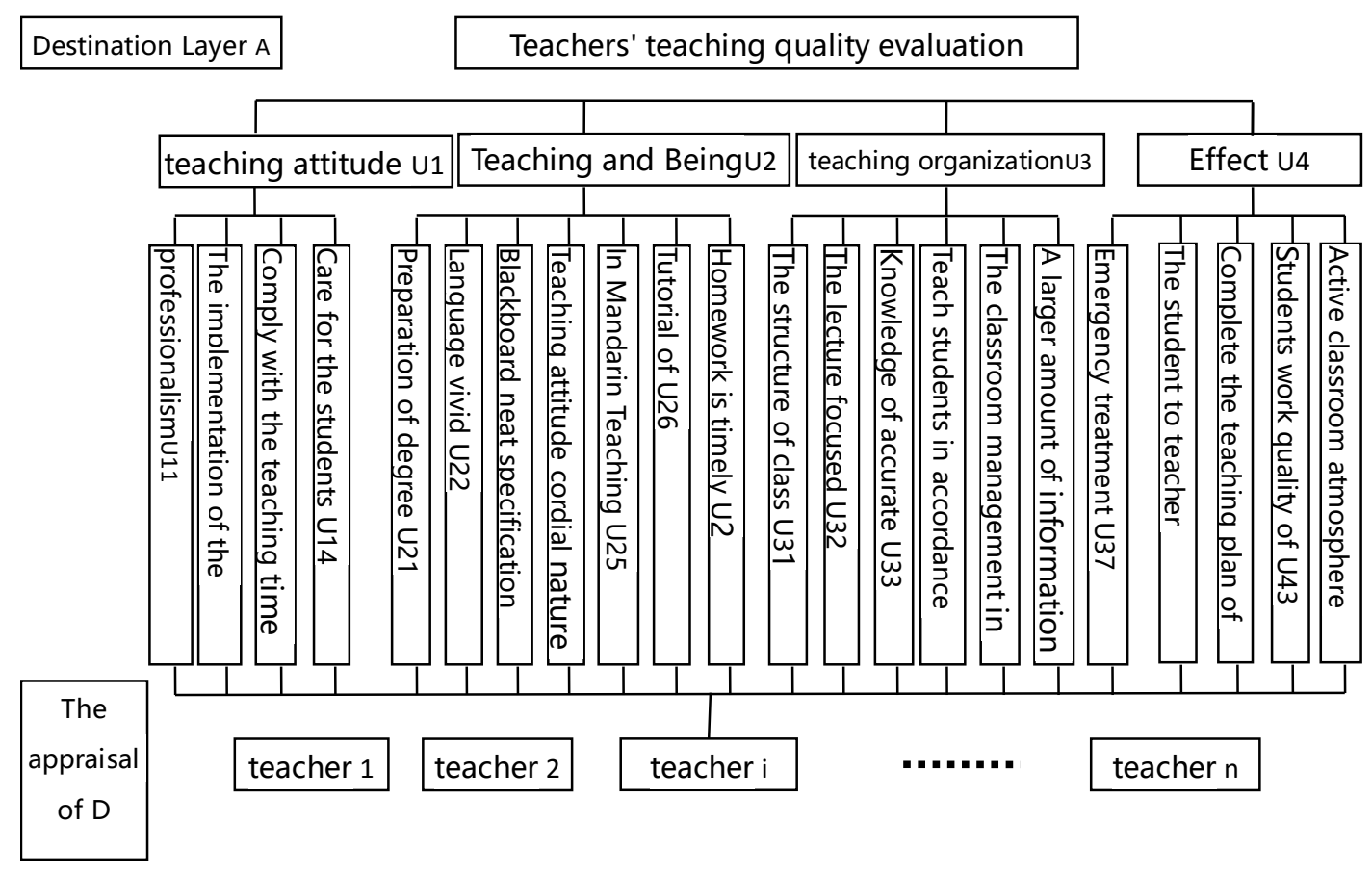

Fig. 1 The structure of teachers' teaching quality evaluation map

\subsection{Construction of two two comparison judgment matrix.}

After establishing the hierarchical structure, subordination between upper and lower level elements can be identified. In this layer, according to the independent college's own characteristics, determine the corresponding judgment matrix. The following table 1-5.

Table 1 teaching attitude positive reciprocal judgment matrix:

\begin{tabular}{lllll}
\hline & $\mathrm{U}_{11}$ & $\mathrm{U}_{12}$ & $\mathrm{U}_{13}$ & $\mathrm{U}_{14}$ \\
\hline $\mathrm{U}_{11}$ & 1 & 3 & 5 & 7 \\
$\mathrm{U}_{12}$ & $1 / 3$ & 1 & 2 & 4 \\
$\mathrm{U}_{13}$ & $1 / 5$ & $1 / 2$ & 1 & 3 \\
$\mathrm{U}_{14}$ & $1 / 7$ & $1 / 4$ & $1 / 3$ & 1 \\
\hline
\end{tabular}


Table 2 basic skills, teaching the positive reciprocal judgment matrix:

\begin{tabular}{cccccccc}
\hline & $\mathrm{U}_{21}$ & $\mathrm{U}_{22}$ & $\mathrm{U}_{23}$ & $\mathrm{U}_{24}$ & $\mathrm{U}_{25}$ & $\mathrm{U}_{26}$ & $\mathrm{U}_{27}$ \\
\hline $\mathrm{U}_{21}$ & 1 & 2 & 3 & 5 & 6 & 7 & 4 \\
$\mathrm{U}_{22}$ & $1 / 2$ & 1 & 2 & 4 & 5 & 6 & 3 \\
$\mathrm{U}_{23}$ & $1 / 3$ & $1 / 2$ & 1 & 5 & 4 & 2 & 3 \\
$\mathrm{U}_{24}$ & $1 / 5$ & $1 / 4$ & $1 / 3$ & 1 & 2 & 4 & 5 \\
$\mathrm{U}_{25}$ & $1 / 6$ & $1 / 5$ & $1 / 4$ & $1 / 2$ & 1 & 4 & 7 \\
$\mathrm{U}_{26}$ & $1 / 7$ & $1 / 6$ & $1 / 2$ & $1 / 4$ & $1 / 4$ & 1 & 2 \\
$\mathrm{U}_{27}$ & $1 / 4$ & $1 / 3$ & $1 / 3$ & $1 / 5$ & $1 / 7$ & $1 / 2$ & 1 \\
\hline
\end{tabular}

Table 4 the teaching effect of the positive reciprocal judgment matrix:

\begin{tabular}{ccccc}
\hline & $\mathrm{U}_{41}$ & $\mathrm{U}_{42}$ & $\mathrm{U}_{43}$ & $\mathrm{U}_{44}$ \\
\hline $\mathrm{U}_{41}$ & 1 & 2 & 3 & 5 \\
$\mathrm{U}_{42}$ & $1 / 2$ & 1 & 2 & 4 \\
$\mathrm{U}_{43}$ & $1 / 3$ & $1 / 2$ & 1 & 5 \\
$\mathrm{U}_{44}$ & $1 / 5$ & $1 / 4$ & $1 / 5$ & 1 \\
\hline
\end{tabular}

Table 3 the teaching organization reciprocal judgment matrix:

\begin{tabular}{cccccccc}
\hline & $\mathrm{U}_{31}$ & $\mathrm{U}_{32}$ & $\mathrm{U}_{33}$ & $\mathrm{U}_{34}$ & $\mathrm{U}_{35}$ & $\mathrm{U}_{36}$ & $\mathrm{U}_{37}$ \\
\hline $\mathrm{U}_{31}$ & 1 & 3 & 4 & 3 & 2 & 5 & 2 \\
$\mathrm{U}_{32}$ & $1 / 3$ & 1 & 3 & 2 & 5 & 4 & 1 \\
$\mathrm{U}_{33}$ & $1 / 4$ & $1 / 3$ & 1 & 5 & 6 & 7 & 8 \\
$\mathrm{U}_{34}$ & $1 / 3$ & $1 / 2$ & $1 / 5$ & 1 & 2 & 4 & 6 \\
$\mathrm{U}_{35}$ & $1 / 2$ & $1 / 5$ & $1 / 6$ & $1 / 2$ & 1 & 3 & 5 \\
$\mathrm{U}_{36}$ & $1 / 5$ & $1 / 4$ & $1 / 7$ & $1 / 4$ & $1 / 3$ & 1 & 4 \\
$\mathrm{U}_{37}$ & $1 / 2$ & 1 & $1 / 8$ & $1 / 6$ & $1 / 5$ & $1 / 4$ & 1 \\
\hline
\end{tabular}

Table 5 the teacher teaching comprehensive reciprocal judgment matrices:

\begin{tabular}{ccccc}
\hline & $\mathrm{U}_{1}$ & $\mathrm{U}_{2}$ & $\mathrm{U}_{3}$ & $\mathrm{U}_{4}$ \\
\hline $\mathrm{U}_{1}$ & 1 & 3 & 3 & 2 \\
$\mathrm{U}_{2}$ & $1 / 3$ & 1 & 2 & 3 \\
$\mathrm{U}_{3}$ & $1 / 3$ & $1 / 2$ & 1 & 1 \\
$\mathrm{U}_{4}$ & $1 / 2$ & $1 / 3$ & 1 & 1 \\
\hline
\end{tabular}

\subsection{Calculation of weights of different criterion layer element}

The determination of the weight is the key to reasonable evaluation of teaching quality. A lot of determining weights method, the judgment matrix through Shangbu established, solving the maximum eigenvalue and eigenvector, get the index of the level relative to the weight of a hierarchy of criteria, finally get the weights of indexes in the whole system.

(1). According to the index system of evaluation and judgment matrix set up above, can their weight coefficients determined by teaching attitude, judgment matrix as an example, the calculation steps are as follows:

(1)Matrix Mi for product:

$$
\begin{aligned}
M_{1} & =1 \times 3 \times 5 \times 7=105 \\
M_{2} & =\frac{1}{3} \times 1 \times 2 \times 4=\frac{8}{3} \\
M_{a} & =\frac{1}{5} \times \frac{1}{2} \times 1 \times 3=\frac{3}{10} \\
M_{4} & =\frac{1}{7} \times \frac{1}{4} \times \frac{1}{4} \times 1=\frac{1}{112}
\end{aligned}
$$

(2) The root of $\mathrm{n} \mathrm{M}^{\prime} 1$ calculation, $\mathrm{W}^{\prime} 1=3.2011, \mathrm{~W}^{\prime} 2=1.2779, \mathrm{~W}^{\prime} 3=0.7401, \mathrm{~W}^{\prime} 4=0.3303$

(3)The W1 standardization, $W_{\mathrm{i}}=\frac{\mathrm{W}_{i}^{0}}{\sum_{j=1}^{m} \mathrm{~W}_{i}^{0}}$ 有: W1=0.4174,W2=0.2532,W3=0.1972,W4=0.1322

(4)The greatest characteristic root for judgment matrix:

$$
\lambda_{\max }=\frac{1}{m} \sum_{i=1}^{m} \frac{\sum_{j=1}^{n} a_{i j} w_{j}}{w_{i}} \text {, 有 } \lambda_{\max }=4.066
$$

(5)Definition of consistency index:

$$
\mathrm{CI}=\frac{\lambda_{\max }-\mathrm{n}}{\mathrm{n}-1}=\frac{4.066-4}{3}=0.022
$$

(6) The introduction of random index $\mathrm{RI}=0.95$, so the consistency ratio:

$$
\mathrm{CR}=\frac{C I}{R I}=\frac{0.022}{0.95}=0.023
$$

Check the consistency of the $\mathrm{CR}<0.1$, therefore, the consistency of judgment matrix is satisfied, then obtains the element characteristics of vector teaching attitude in index (weight vectors) for:

$\mathrm{W} 1=(0.4174,0.2532,0.1972,0.1322)$ 
(2) Similarly, we can calculate the element characteristics of basic skills in the teaching of vector index (weight vectors) for:

W2 $=0.2411,0.1974,0.1616,0.1214,0.1180,0.0814,0.0791)$

Each element in the feature vector teaching organization index (weight vectors) for:

W3 $=0.1940,0.1682,0.2175,0.1417,0.1160,0.0872,0.0756$

The element characteristics of vector teaching effect in index (weight vectors) for:

W4 $=0.3371,0.2760,0.2498,0.1371$

\subsection{The teachers' teaching quality evaluation}

For simplicity, the assumption here is only A, B, C three teachers participating, to choose teaching masters. The Organization Department of the school leaders, teachers and students of the three teachers teaching quality scoring evaluation, comparative evaluation using two two, finally obtains the judgment matrix A, B, C are shown in Table 6.

Table 6 A, B, C judgment matrix

\begin{tabular}{|l|l|l|l|l|l|l|l|l|l|l|l|l|l|l|l|}
\hline $\mathrm{U}_{11}$ & $\mathrm{~A}$ & $\mathrm{~B}$ & $\mathrm{C}$ & value & $\mathrm{U}_{12}$ & $\mathrm{~A}$ & $\mathrm{~B}$ & $\mathrm{C}$ & value & $\mathrm{U}_{13}$ & $\mathrm{~A}$ & $\mathrm{~B}$ & $\mathrm{C}$ & value \\
\hline $\mathrm{A}$ & 1 & 2 & 4 & 0.4224 & $\mathrm{~A}$ & 1 & $1 / 4$ & 3 & 0.3057 & $\mathrm{~A}$ & 1 & 3 & 5 & 0.4762 \\
\hline $\mathrm{B}$ & $1 / 2$ & 1 & 3 & 0.3458 & $\mathrm{~B}$ & 4 & 1 & 2 & 0.4267 & $\mathrm{~B}$ & $1 / 3$ & 1 & 1 & 0.2793 \\
\hline $\mathrm{C}$ & $1 / 4$ & $1 / 3$ & 1 & 0.2318 & $\mathrm{C}$ & $1 / 3$ & $1 / 2$ & 1 & 0.2676 & $\mathrm{C}$ & $1 / 5$ & 1 & 1 & 0.2445 \\
\hline $\mathrm{U}_{14}$ & $\mathrm{~A}$ & $\mathrm{~B}$ & $\mathrm{C}$ & value & $\mathrm{U}_{21}$ & $\mathrm{~A}$ & $\mathrm{~B}$ & $\mathrm{C}$ & value & $\mathrm{U}_{22}$ & $\mathrm{~A}$ & $\mathrm{~B}$ & $\mathrm{C}$ & value \\
\hline $\mathrm{A}$ & 1 & 2 & 3 & 0.4018 & $\mathrm{~A}$ & 1 & 3 & 4 & 0.4506 & $\mathrm{~A}$ & 1 & $1 / 4$ & $1 / 2$ & 0.2494 \\
\hline $\mathrm{B}$ & $1 / 2$ & 1 & 2 & 0.3289 & $\mathrm{~B}$ & $1 / 3$ & 1 & 2 & 0.3021 & $\mathrm{~B}$ & 4 & 1 & 2 & 0.4251 \\
\hline $\mathrm{C}$ & $1 / 3$ & $1 / 2$ & 1 & 0.2693 & $\mathrm{C}$ & $1 / 4$ & $1 / 2$ & 1 & 0.2473 & $\mathrm{C}$ & 2 & $1 / 2$ & 1 & 0.3256 \\
\hline $\mathrm{U}_{23}$ & $\mathrm{~A}$ & $\mathrm{~B}$ & $\mathrm{C}$ & value & $\mathrm{U}_{24}$ & $\mathrm{~A}$ & $\mathrm{~B}$ & $\mathrm{C}$ & value & $\mathrm{U}_{25}$ & $\mathrm{~A}$ & $\mathrm{~B}$ & $\mathrm{C}$ & value \\
\hline $\mathrm{A}$ & 1 & 3 & 2 & 0.3996 & $\mathrm{~A}$ & 1 & 3 & 2 & 0.3996 & $\mathrm{~A}$ & 1 & $1 / 3$ & 2 & 0.3114 \\
\hline $\mathrm{B}$ & $1 / 3$ & 1 & 4 & 0.3498 & $\mathrm{~B}$ & $1 / 3$ & 1 & 4 & 0.3498 & $\mathrm{~B}$ & 3 & 1 & $1 / 2$ & 0.3558 \\
\hline $\mathrm{C}$ & $1 / 2$ & $1 / 4$ & 1 & 0.2506 & $\mathrm{C}$ & $1 / 2$ & $1 / 4$ & 1 & 0.2506 & $\mathrm{C}$ & $1 / 2$ & 2 & 1 & 0.3328 \\
\hline $\mathrm{U}_{26}$ & $\mathrm{~A}$ & $\mathrm{~B}$ & $\mathrm{C}$ & value & $\mathrm{U}_{27}$ & $\mathrm{~A}$ & $\mathrm{~B}$ & $\mathrm{C}$ & value & $\mathrm{U}$ & $\mathrm{A}$ & $\mathrm{A}$ & $\mathrm{B}$ & $\mathrm{C}$ & value \\
\hline $\mathrm{A}$ & 1 & $1 / 2$ & $1 / 4$ & 0.2473 & $\mathrm{~A}$ & 1 & 2 & 3 & 0.3965 & $\mathrm{~A}$ & 1 & 5 & 2 & 0.4517 \\
\hline $\mathrm{B}$ & 2 & 1 & $1 / 3$ & 0.3021 & $\mathrm{~B}$ & $1 / 2$ & 1 & 4 & 0.3709 & $\mathrm{~B}$ & $1 / 5$ & 1 & 2 & 0.2650 \\
\hline $\mathrm{C}$ & 4 & 3 & 1 & 0.4506 & $\mathrm{C}$ & $1 / 3$ & $1 / 4$ & 1 & 0.2326 & $\mathrm{C}$ & $1 / 2$ & $1 / 2$ & 1 & 0.2833 \\
\hline
\end{tabular}

According to the table of judgment matrix consistency test and score, calculated the consistency ratio is less than 0.1 , finally by using the weighted average method, obtains the comprehensive evaluation results of every through various elements of comprehensive weight and evaluation object elements score (weight):

A: $0.3801, \mathrm{~B}: 0.3421, \mathrm{C}: 0.2778$

From the comprehensive evaluation results can be seen, the minimum weight $\mathrm{C}$, a highest weight ${ }^{[3]}$. This evaluation method can avoid the lack of subjective evaluation method of data analysis of the traditional, more reasonable, accurate to the teacher's evaluation, the mechanism of equal competition effect, thereby increasing the enthusiasm of teachers. Finally to the independent college teaching work to improve.

\section{5 analytic hierarchy process should pay attention to in the evaluation of teaching quality in Independent Colleges problems}

Although the hierarchy analysis method is a method of teaching quality evaluation is very good, but the application should pay attention to its application prerequisite.

(1) different evaluation objects should follow different evaluation standards to meet the level analysis method, the comparability requirements. The analytic hierarchy process is mainly by means of the concept of relative index, in the evaluation must pay attention to according to different evaluation objects, in accordance with their corresponding responsibilities using different evaluation standard of ${ }^{[4]}$. For the independent college teachers, often sixty percent is own teacher, and the forty percent is the external teacher, then the external teachers and private teachers we can not generally use the same evaluation standard.

(2) the use of hierarchy, levels when constructing model or index can not be too complex, otherwise it will increase the difficulty of evaluation evaluation can easily lead to confusion. The analytic hierarchy process itself by the hierarchical structure and factors that can not be too restrictive, 
and the independent college teacher group is a newly formed and will continue development of the team, if only individually by using the analytic hierarchy process, with the growing ranks of teachers, the workload will be more and more big, if of judgment requires itself does not need too accurate, completely can be combined with other methods of evaluation. Using the method of analytic hierarchy process before, by some other methods and means to reduce the hierarchical structure and narrow the scope of the appraisal object. ${ }^{[5]}$

\section{Summary}

In short, the teaching quality evaluation using the AHP to teachers of independent college is a good method, combining the evaluation and mathematical evaluation method of competent organic, overcomes many shortcomings of traditional method, but also a premise of its application ${ }^{[6]}$. Each independent colleges in the teachers' quality assessment process should be combined with its own characteristics of reasonable design of evaluation index system and hierarchical structure, foster strengths and circumvent weaknesses, flexibility in the use of. Which can effectively help to improve the teaching level of teachers, and to the development of college may also play a role in promoting, eventually making in the fierce competition in the market can remain invincible in independent college $^{[7]}$.

\section{References}

[1]. Ivana Roháčová, Zuzana Marková. The Analysis of AHP method and its potential use in logistics[J]. Acta Montanistica Slovaca, 2009, 14(1).

[2]. Dohoon Kim. An integrated framework of HoQ and AHP for the QOE improvement of network-based ASP services[J]. annals of telecommunications - annales des télécommunications, 2010, 65(1).

[3]. Sima Ajami, Saeedeh Ketabi. Performance Evaluation of Medical Records Departments by Analytical Hierarchy Process (AHP) Approach in the Selected Hospitals in Isfahan[J]. Journal of Medical Systems, 2012, 36(3).

[4]. Bojan Srdjevic, Yvonilde Dantas Pinto Medeiros. Fuzzy AHP Assessment of Water Management Plans[J]. Water Resources Management, 2008, 22(7).

[5]. Martínez, E. , Álvarez, M. , Arquero, Á. et al.. Apoyo a la selección de emplazamientos óptimos de edificios. Localización de un edificio universitario mediante el Proceso Analítico Jerárquico (AHP)[J]. Informes de la Construccion, 2010, 62(519).

[6]. Motik Darko, Šegotić Ksenija, Jazbec Anamarija. Application of AHP Model and Survey Results in Deciding on a Product Line in Furniture Industry[J]. Drvna industrija, 2010, 61(2).

[7]. Huu Tuan Do, Shang-Lien Lo, Lan Anh Phan Thi. Calculating of river water quality sampling frequency by the analytic hierarchy process (AHP)[J]. Environmental Monitoring and Assessment, 2013, 185(1). 